Sistema e ONTOLOGIA NA FILOSOFIA FrAnCESA CONTEMPORÂNEA (II)

\title{
Método ou sistema? Por uma metafísica local
}

Method or System?

*Elie During

Resumo: Precisão, análise, enquete: estas noções carregam uma ideia da filosofia que mesmo os mais convencidos dos bergsonistas têm dificuldade para sustentar na prática, tão forte é a pressão que pesa sobre cada um para produzir uma filosofia identificável, suscetível de encontrar seu lugar no jogo dos sistemas. É que nas condições fixadas por Bergson, não poderia existir sistema senão "por provisão", o tempo de uma questão.

Palavras-chave: Bergson. Deleuze. James. Einstein. "Block-universe".

Abstract: Precision, analysis, inquiry: these notions carry an idea of philosophy that even the most convinced of Bergsonians have trouble defending in practice, such is the pressure weighing on everyone to produce an identifiable philosophy able to find its place in the game of systems. The fact is that according to the very conditions set by Bergson, there could only be a system "provisionally", that is, for the time of a question.

Keywords: Bergson. Deleuze. James. Einstein. "Block-universe".

\footnotetext{
* Doutor pela Université de Paris 10 Nanterre. Professor de Filosofia na Université Paris 10 Nanterre, no European Graduate School e Professor visitante na École des Beaux Arts de Paris.<eduring@u-paris10.fr>.
} 
"Quando começo um trabalho novo, é porque encontrei no trabalho precedente uma dificuldade. Eu sei que eu estou no verdadeiro para tal coisa, mas... eu gostaria muito de saber o que se passa aqui (o filósofo mostra um ponto preciso, em sua mão doente). Eu o deixo de lado provisoriamente: quando isto estiver terminado, eu voltarei, eu tentarei elucidar este ponto (ele balança a cabeça com um ar decidido).

Eu não consigo formular a dificuldade: é um buraco negro. Ele se torna para mim um centro: há aí algo de obscuro que é necessário esclarecer! Eu circundo este ponto negro. Eu descrevo em torno dele uma circunferência, visando o buraco que está no centro, os diferentes pontos da circunferência." 1

\section{O método: o caso Bergson}

Ne o espírito da filosofia francesa deve alguma coisa a Descartes, é $\checkmark$ de ter sabido opor às pretensões exorbitantes do sistema o rigor de um método - ou ao menos, de ter subordinado o primeiro ao segundo. Ainda é necessário compreender estas palavras. Bergson, o último de nossos grandes filósofos que teve a coragem de afirmar em alto e bom tom a necessidade da metafísica, revindicava para esta uma virtude de precisão que geralmente lhe falta quando esta é apresentada como uma vasta dialética de conceitos. Para este novo "cavaleiro francês", segundo a expressão de Péguy, tratava-se de um exercício superior da inteligência. Mas a este termo antigo, cuja etimologia (inter, legere) nos remete à faculdade de ler entre as linhas, de discernir e de recortar as linhas, sabemos que ele preferiu finalmente aquele de "intuição", ao preço de alguns duráveis mal-entendidos.

Nós fizemos do bergsonismo um anti-intelectualismo, como se a recusa de atribuir por fim à filosofia a edificação de um sistema condenasse o pensador a abdicar de toda visada de elucidação racional em proveito de amáveis tours de retórica; como se a "experiência integral", que é para Bergson o outro nome da metafísica, ${ }^{2}$ devesse necessariamente se traduzir pela exposição sintética de uma "verdade integral" sob a forma de um sistema que tem resposta para tudo. ${ }^{3}$

${ }^{1}$ Henri Bergson, de acordo com Lydie Adolphe, La Dialectique des images chez Bergson, Paris: PUF, 1951, p. 3.

${ }^{2}$ Henri Bergson, La Pensée et le mouvant [1934], Paris: PUF, 2009, p. 227. Se trata aqui de visar uma experiência não reduzida, não disposta às formas de inteligência comuns; uma experiência que faria jus à dimensão de duração pela qual as coisas fazem-se, isto é, criam-se, conforme a ideia de uma "criação contínua de novidade imprevisível" (p. 99).

3 Ver a entrevista de 13 de julho de 1926 com Jacques Chevalier, in Jacques Chevalier, Entretiens avec Bergson, Paris: Plon, 1959, p. 75. 
Mas justamente, se o método da intuição - a intuição como método, segundo a fórmula de Deleuze ${ }^{4}$ - visa a experiência integral, se ela ambiciona pensar toda coisa contanto que ela participe de todo o resto (e notadamente ao Todo do universo), - sua abordagem permanece fundamentalmente analítica, desde que ela se empenhe em pensar formações impuras, mistos mal analisados, se esforçando para reencontrar a cada vez, em casos bem determinados, as articulações naturais às quais um corte muito sistemático arrisca sempre de substituir uma combinação de noções gerais. Analisar, para Bergson, é efetuar diferenciações qualitativas, isolar tendências puras identificando direções em estado nascente. Assim é quando ele se confronta com o problema clássico da relação da alma e do corpo: é através do fenômeno da memória que ele começa a apertar a natureza do espirito, em sua relação com a matéria; e é a questão da afasia, visada "no ponto onde a atividade da matéria quase atinge aquela do espírito", ${ }^{5}$ que lhe permite reformular uma posição dualista, sem ter de recorrer para isto à clássica oposição entre substância pensante e substância extensa. O filósofo dispensa conceitos de espírito e de matéria em geral: ao gênero da dissertação ele substitui o da enquete. Seu exame minucioso das funções da memória e do cérebro o conduz a algumas teses surpreendentes, que nada permitia deduzir a priori. A vida da consciência é feita apenas de movimentos de espiritualização e de materialização, de virtualização e de atualização; sua atividade se organiza sobre uma pluralidade de "planos" diferenciados por graus de tensão; o passado se conserva integralmente em si sob a forma da "lembrança pura", etc.

Precisão, análise, enquete: estas noções carregam uma ideia da filosofia que mesmo os mais convencidos dos bergsonistas têm dificuldade para sustentar na prática, tão forte é a pressão que pesa sobre cada um

4 "Sem a intuição como método, a duração permaneceria uma simples experiência psicológica". (Gilles Deleuze, Le bergsonisme, Paris: PUF, 1966, p. 25).

5 A valorização da análise como trabalho de discernimento e de diferenciação não contradiz de forma alguma a crítica da decomposição artificial da experiência pela inteligência fabricante. Não devemos esquecer, de fato, que "a dialética é necessária para colocar a intuição à prova, necessária também para que a intuição se refrate em conceitos e se propague a outros homens" (L'Évolution créatrice [1907], Paris: PUF, 2007, p. 239). Esta necessidade não é somente de ordem pragmática, ela diz respeito à natureza mesma deste exercício contrariado da inteligência que Bergson chama "intuição". O enraizamento experiencial sempre se traduz, no fim das contas, por um trabalho sobre os conceitos, mesmo se isso passe por "flexibilizações" (assouplissements) que lhe permitirão expressar a diferenciação intensiva de tendências imanente ao real. Mais profundamente, a intuição só pode ser feita e conquistada através de tramas de experiência que já impliquem uma formatação simbólica do dado. De outra forma compreenderíamos mal o trabalho que teve Bergson para precisar a intuição em contato com as ciências de seu tempo. Ver Camille Riquier, Archéologie de Bergson, Paris: PUF, 2009, p. 253 s, e também Frédéric Fruteau de Laclos, "La philosophie analytique d'Henri Bergson", in Lire Bergson, C. Riquier \& F. Worms (dir.), Paris: PUF, 2011. 
para produzir uma filosofia identificável, suscetível de encontrar seu lugar no jogo dos sistemas. É que nas condições fixadas por Bergson, não poderia existir sistema senão "por provisão", ${ }^{6}$ o tempo de uma questão. Que se trate aí do contrário do amadorismo, ${ }^{7}$ tornou-se difícil de compreendê-lo em um tempo em que a proliferação de pequenos sistemas tem a tendência de fazer perder de vista a questão do método utilizado para os produzir. Cada um se vale hoje de seu "pequeno tratado", oferecendo sob uma forma falsamente modesta um condensado de visão de mundo, um resumo lúdico das primeiras e últimas questões. Mesmo o autor de uma Metafísica do cigarro ou de uma Ontologia do pêlo tem, no entanto, dificuldade de dissimular, sob a escolha de um objeto derrisório ou anedótico, a ambição de um sistema que não terá talvez a força de produzir mas que permanece, malgrado as declarações atroadoras sobre o fim da filosofia ou da metafísica, a norma em relação à qual se define seu regime de escrita aforística. ${ }^{8}$

Mas sejamos precisos, posto que é necessário sê-lo. Se nós perguntássemos o que significa, concretamente, substituir o método pelo sistema, se nós quiséssemos definir em poucas palavras os princípios do método bergsoniano, eis o que seria necessário dizer: este método procede por estreitamento dos problemas ${ }^{9}$ e recorte de linhas de fatos. ${ }^{10}$ Ele se funda sobre "a convicção de que a filosofia, malgrado a desordem aparente dos sistemas, gravita entorno de um objeto fixo que ela encerra dentro de círculos cada vez mais estreitos". ${ }^{11}$ Mas este objeto, quer se trate da duração ou da vida, se transforma em prática através de uma diversidade de problemas que o filósofo não pode senão visar por partes, segundo ângulos de corte diferentes a cada vez. Reconhecemos

${ }^{6}$ René Descartes, carta-prefácio à edição francesa do Principes de la philosophie.

7 Sobre este ponto, ver a carta à Floris Delattre de dezembro de 1935: "Chamo amador aquele que escolhe entre soluções já dadas, tal como escolhemos o partido político em que nos inscreveremos. E chamo filósofo aquele que cria a solução, necessariamente única, do problema que ele coloca novamente, justamente porque fazia esforço para resolvê-lo." (Écrits, op. cit., p. 682).

8 Encontraríamos uma confirmação desta tendência nos títulos de alguns trabalhos de Alain Badiou que é, ademais, um dos únicos filósofos a ter dado, nos últimos anos, uma forma efetiva à sua ambição sistemática: Breve tratado de ontologia transitória (piscar de olhos a Spinoza), Pequeno Manual d'inestética, etc.

9 Bergson explicita longamente, de acordo com exemplos, este método de apertamento no texto já citado "Le parallélisme psycho-physique et la métaphysique positive".

10 "Sempre pensei desta maneira: me colocando sobre os pontos daquilo que só se revelou circunferência mais tarde, e de lá visando o centro, através de um método de cruzamento. Todas essas linhas de visada devem convergir para um mesmo ponto. (Henri Bergson, citado por Jacques Chevalier, op. cit., p. 273). Sobre o método do recorte (ou de "corte" ("recoupage"), ver igualmente Jean de La Harpe, "Souvenirs personnels d'un entretien avec Bergson", in A. Béguin et P. Thévenaz (dir.), Henri Bergson: essais et témoignages inédits, Neuchâtel: La Baconnière, 1941, p. 361-362.

${ }^{11}$ Henri Bergson, "Sur un ouvrage de Paul Janet", in Écrits, Paris: PUF, 2011, p. 211. 
neste traço o empirismo de Bergson, seu lado British, tão pouco alemão. $O$ vivo interesse que ele mantinha pelos mais recentes avanços das ciências empíricas de seu tempo - não esqueçamos que ele é o primeiro na França a ter consagrado um livro de filosofia à bastante jovem teoria da relatividade - possuía evidentemente relação com a concepção mesma que ele se fazia da atividade filosófica. Em resposta a um crítico um pouco obtuso, eis o que ele escrevia: "Temo fortemente que não seja isto o que nos separa, e que você se representaria (malgrado você mesmo) a metafísica como uma ciência análoga às matemáticas, obrigada à simplicidade clara e ao dogmatismo incisivo das matemáticas. Se a metafísica é isto, temos apenas que escolher entre concepções definitivamente estagnantes, simples, das quais nós pressionaremos o desenvolvimento até o final: é uma ciência feita, ou ainda, é apenas um jogo regrado entre escolas antagonistas que alçam juntas à cena, para fazer-se aplaudir cada vez. Eu vejo, ao contrário, na metafísica por vir, uma ciência empírica à sua maneira, progressiva, obrigada como as outras ciências positivas a dar como apenas por provisoriamente definitivos os últimos resultados aos quais ela terá sido conduzida por um estudo atento do real. Foi em resultados deste gênero que parei. ${ }^{12}$

"Provisoriamente definitivo": tal seria finalmente a fórmula do sistema bergsoniano, refratado no prisma do método. Neste contexto, a referência cartesiana é profundamente ambivalente, uma vez que em Bergson ele mesmo ela serve frequentemente a identificar o projeto, ilegítimo aos seus olhos, de uma "ciência única da natureza", de uma "grande matemática capaz de tudo abarcar". É verdade que esta interpretação da mathesis universalis é majoritariamente atribuída aos "sucessores de Descartes, levando às suas extremas consequências as teorias do mestre". ${ }^{13}$ Mas o método cartesiano naturalmente se prestava a tal, e é também assim que se reconhece um certo espírito da filosofia francesa, seu mal espírito, sua arrogância própria: a certeza de poder finalmente responder à tudo, contanto que saibamos conduzir sua razão. Ora, o método da "metafísica positiva" - Bergson entende por isto uma metafísica calcada sobre o terreno da experiência - supõe "que nós vamos progressivamente às idéias através do longo e duro caminho dos fatos". ${ }^{14} \mathrm{E}$ os fatos não são apenas "teimosos", segundo a palavra de Lênin: eles são igualmente dissociados e dispersos, de maneira que é necessário começar por recolhê-los, reuni-los segundo "linhas de fatos", para conseguir em seguida, ao preço de tentativas às vezes trabalhosas, e sem anular a

\footnotetext{
${ }^{12}$ Henri Bergson, "Le parallélisme psycho-physique et la métaphysique positive", in Écrits, op. cit., p. 249.

${ }^{13}$ Ibid., p. 251.

${ }^{14}$ Ibid., p. 254.
} 
heterogeneidade do dado, fazê-los convergir em direção a um alvo. ${ }^{15}$ Isto significa que se a filosofia incide virtualmente sobre tudo, isto é, sobre qualquer coisa, não significa que ela fale de tudo ao mesmo tempo, mas que fora procedendo em ordem, seriando as dificuldades. Dito de outra maneira, ela só pode abordar seus problemas um a um, e dentro de um estado de relativa dispersão: isto constitui talvez a melhor definição operatória de um método que não visaria implantar um sistema. ${ }^{16}$

Bergson tinha plenamente consciência da originalidade desta abordagem, que devia conduzir, segundo ele, à uma nova idéia da cooperação intelectual: "Aí está, dizia ele, minha principal inovação, uma filosofia sendo geralmente considerada como devendo, ao contrário, ser um sistema e conter, por consequência, a solução ao menos implícita de todos os problemas. Preocupei-me em dizer que esta filosofia aqui admite e mesmo demanda colaboração como o faz a ciência". ${ }^{17} \mathrm{Um}$ depoimento de Gabriel Marcel confirma esta orientação: "Henri Bergson falava de seus trabalhos, não de sua obra, e me parece que esta nuance de vocabulário diz tudo. [...] Há aí uma disposição de espírito talvez incompatível com uma crença que não foi jamais a sua, a crença na possibilidade e no valor da exposição sistemática de um certo corpus de proposições pelo qual o filósofo traduziria ou extrairia a essência da realidade". ${ }^{18}$ Que o bergsonismo, recuperado através da obra feita, possa ser o objeto de exposições "sistemáticas", pretendendo remeter um pensamento a "um pequeno número de afirmações centrais de onde todo o resto se deduzia analiticamente", ${ }^{19}$ é uma tentação natural. O conceito de duração, a imagem do élan vital, se prestem a este tipo de exercício. Os convocamos como categorias primeiras ou como princípios cujo o resto deveria se deduzir por simples decomposição e recombinação de conceitos, apoiando-se sobre algumas experiências

15 "A intuição não é uma inspiração vinda de cima, é uma abordagem que consiste em pular no centro, depois de olhar de todos os pontos" (por Lydie Adolphe, op. cit., p. 5).

${ }^{16}$ Além do mais é duvidoso, deste ponto de vista, que pudéssemos encontrar em Bergson algo como uma ontologia geral em sentido estrito, mobilizando os recursos da linguagem para falar do ser tomado em sua universalidade. Se uma tal ontologia existe (ontologia do virtual, da diferença?), é necessário reconhecer que ela é singularmente pobre. Ela consiste em reconhecer que o fundo do ser é duração (multiplicidade qualitativa), acrescentando ainda que existem apenas durações, forçosamente qualificadas e singulares, das quais é pouco útil falar de maneira geral a não ser para delas extrair modos de relação ou de coexistência que dizem respeito mais a uma filosofia da natureza do que a uma ontologia. Bergson, sobre este ponto, mantém-se fundamentalmente nominalista. Falar-se do ser em geral não demonstra, estritamente, nenhum interesse, se não para chegar-se às tendências metafísicas herdadas de Aristóteles ou de Kant. Seria necessário falar, neste sentido, de uma ontologia negativa.

${ }^{17}$ Citado por Jacques Chevalier, op. cit., p. 75.

${ }^{18}$ Gabriel Marcel, "Grandeur de Bergson", in Henri Bergson: essais et témoignages inédits, A. Béguin et P. Thévenaz (dir.), Neuchâtel, La Baconnière, 1941, p. 29.

${ }^{19}$ Ibid. 
privilegiadas, capazes de dar o impulso necessário ao movimento do pensamento. Bergson ele mesmo às vezes sacrificou regularmente quem quisesse que nós soubéssemos resumir uma doutrina à atenção dos jornalistas ou das pessoas em geral por uma ou duas fórmulas marcantes. Lembramos que, a uma senhora que lhe pedia para resumir seu pensamento em algumas palavras que ela pudesse compreender, ele deu esta resposta lapidar: "Eu disse que o tempo era real, e que ele não era do espaço".

Mas o bergsonismo a posteriori tem sempre algo de arbitrário e de opaco, tanto que não recuperamos a necessidade local das questões, segundo a ordem de sua descoberta. É o que torna tão difícil a transmissão da filosofia bergsoniana: ela não tem nada de um corpus de doutrina; mas se apresenta de um livro a outro - e seu autor insistia sobre o fato de que se tratava de "ensaios" -, como uma multiplicidade de sistemas "provisoriamente definitivos" que são como tantas versões possíveis de um sistema aberto, jamais estabilizado, e na verdade sequer parte alguma formulado. ${ }^{20}$ Este pensamento exige que o reinventemos cada vez por nossa conta, a fim de levá-lo a novos terrenos.

\section{Como as coisas mantêm-se juntas}

No entanto, tomar os problemas um a um, falar realmente de tudo, mas nunca em bloco, não é isso precisamente o ideal regulador da filosofia "analítica" que inventou-se no início do século XX entre Viena e Cambridge, em uma relação de companheirismo estreito com o "método científico"? Não fora Russell que reclamava, por sua vez, uma filosofia "em detalhe" (piecemeal), capaz de formular hipóteses provisórias e revisáveis? ${ }^{21} \mathrm{E}$ por quê continuar a falar, neste caso, de metafísica? Sobre isto, no entanto, Bergson nunca modificou seu pensamento, e tal é suficiente para definir as diferenças: "Eu faço apenas metafísica, e acredito realmente poder atestá-lo; nada que não seja metafísica. E se eu emprego esta palavra, é ainda uma concessão à crítica, uma vez que eu gostaria de melhor definir meu esforço como um aprofundamento metafísico da experiência. Mas enfim, dizemos metafísica, posto que

\footnotetext{
${ }^{20}$ A obra de Leibniz nos coloca em uma situação aparentemente simétrica: cada escrito aí aparece como um ponto de vista possível sobre um sistema que de fato se encontra expresso por toda parte.

21 "Uma filosofia científica, tal como eu gostaria de promovê-la, será uma filosofia atenta ao detalhe e provisória, como todas as ciências; ela será, sobretudo, capaz de inventar hipóteses que, mesmo não sendo inteiramente verdadeiras, se manterão no entanto férteis uma vez que lhe tivermos proporcionado as correções necessárias." (Bertrand Russell, "On scientific method in philosophy", in Mysticism and Logic, London, Routledge, 1986, p. 110).
} 
metafísica há".22 O aprofundamento da experiência, a experiência integral, tal é o horizonte no qual se inscreve esta metafísica sem sistema, animada pela preocupação do método. Se trata, por uma parte, de não deixar nada de lado, de abordar o Todo segundo suas dimensões reais, o que compreende também aquelas que se deixam dificilmente reduzir aos formatos da análise lógica ou das línguas formulárias; se trata, por outra parte, de não perder de vista a necessidade de se propor captações do real partindo-se de problemas singulares. Nenhuma relação com o projeto de uma ciência universal que buscaria unificar os resultados dissociados das ciências positivas e produzir, por meio de generalizações cada vez mais amplas, uma sistematização da experiência de acordo com uma síntese de todo o saber. ${ }^{23}$ Mas nenhuma relação também com uma filosofia que se contentaria em acompanhar e em explicitar a construção da objetividade científica renunciando à ambição de abarcar a "experiência integral". Se Bergson é um representante atípico do espírito francês, um continuador paradoxal de Descartes, o é assumindo fortemente a posição de uma metafísica local: uma metafísica que pretende pensar à altura do Todo, mas sempre a partir de uma situação.

Este último tema, bem sabemos, floresceu na tradição existencialista, e não evidentemente sem relação com a abordagem precedente. A questão que é a nossa, essa que nós herdamos em um contexto confuso em que domina uma doxa "pós-moderna" (fim da metafísica, falência geral dos grandes sistemas, etc.), é a de saber como um método rigorosamente assistemático - mais do que anti-sistemático, como compreendemos - pode se unir à preocupação de manter a metafísica em seus direitos e visar - é o menos que podemos esperar dela - um discurso sobre a totalidade? Para melhor entender de que maneira o espírito do empirismo é suscetível de conjugar-se com esta vocação universal - para não dizer "totalizante" - da metafísica, é interessante retomar a relação que Bergson mantém com um de seus contemporâneos mais célebres, cujo nome é associado justamente à renovação da tradição empirista: trata-se claramente de William James. Eis o que diz Bergson: "O que eu forneci à James? Talvez ligações. Nós franceses temos, sentimos a necessidade de colocar, entre as idéias e as coisas, ligações, que além do mais não são necessariamente sistemáticas e que possuem justamente a vantagem de não sê-lo (me esforço, antes de cada um de meus livros, de retomar as coisas, de pensá-las novamente como se eu não houvesse nunca escrito nada). É isto que James encontrou em mim: um método, já bastante aparente em Matéria e Memória, e que sem dúvida o atingiu

\footnotetext{
${ }^{22}$ Considerações de Gilbert Maire, Bergson, mon maître, Paris, Grasset, 1935, p. 216.
}

${ }^{23}$ Conferir as colocações de Bergson em La Pensée et le mouvant, op. cit., p. 134-135. 
ainda mais que as respostas que eu dava sobre um problema que não lhe havia especialmente chamado atenção. Assim, aquilo que até então lhe aparecera somente como observação psicológica lhe apareceu como visão metafísica". ${ }^{24}$

A metafísica oferece ligações; mas é porque ela primeiramente faz ver alguma coisa. Sobre este tema da "vidência" (voyance) como operação filosófica fundamental, sobre sua relação com o imperceptível, Deleuze disse o essencial. Nós gostaríamos de nos concentrar aqui sobre a questão de saber como esta maneira de introduzir entre as coisas relações que não eram percebidas (pensadas), nem mesmo talvez perceptíveis (pensáveis), reage sobre o problema da totalidade, da possibilidade de se referir à existência como a uma totalidade em que as coisas coexistem, em seus diferentes modos de existência, sobre o plano da experiência "integral". Este problema, Bergson havia encontrado em seu diálogo com as ciências contemporâneas; e é ainda amplamente o nosso. Mas a questão da coexistência ou da conexão das coisas (nexus rerum) está, mais frequentemente, no coração de toda empresa metafísica, qualquer que seja a maneira como concebemos a enquete. A causalidade, o espaço, o tempo, e é claro a articulação do espaço e do tempo na forma "espaço-tempo" elaboradas pelos físicos, constituem as formas privilegiadas deste nexus, tomado em sua extensão universal; elas não são provavelmente as únicas, e o espaço-tempo ele mesmo já bem comporta variedades. O que se passa, no entanto, quando nós tomamos este nexus do ponto de vista de uma metafísica assistemática? $\mathrm{Ou}$, para dizer de outra forma, dando ao propósito o caráter mais geral possível: como conciliar o ponto de vista global de um discurso sobre a totalidade e o ponto de vista local associado à idéia de situação?

Todas as ontologias que, de Bergson à Sartre ou Deleuze, quiseram inscrever no coração do ser um princípio de indeterminação radical (duração, projeto, devir, etc.), foram confrontadas com este problema assim que se tratou de manter junta uma multiplicidade de pontos de indeterminação (durações, projetos, devires, etc). Até porque é necessário inscrever o situs em um espaço de situações, sem assim anular a singularidade desta inscrição, seu caráter necessariamente excedentário ou sobre-numerário em vista da ordem ou da necessidade de que somente conhecemos, depois de tudo, figuras locais (as leis da natureza, compreendidas em um determinado estado da ciência). Para exprimir esta exigência problemática, nós recorremos a uma solução instável, sob a forma de um oxímoro: invocamos, de diferentes maneiras, uma "totalidade aberta", uma totalidade que não se fecha sobre ela mesma

$\overline{{ }^{24} \text { Citado por Jacques }}$ Chevalier, op. cit., p. 236. 
porque ela assume e propaga em alguma maneira a indeterminação que está no coração do ser. "Virtual" designa seguidamente para Deleuze este problema, e entendemos que o Todo tenha para ele, como para Bergson, essencialmente relação com o tempo como duração criadora. Mas o ponto importante é que esta duração é antes de tudo princípio de coexistência ou de conexão, ainda que a idéia de sucessão habitualmente associada ao "curso" do tempo tenha aí um papel secundário. ${ }^{25}$ Princípio de coexistência ou de conexão: o compreendemos melhor ao percebermos que toda experiência da duração é fundamentalmente experiência de uma pluralidade de durações, ou mais exatamente de um diferencial de tensão entre duas ou diversas durações. É a lição do célebre exemplo desenvolvido em $A$ Evolução criadora: "é preciso esperar que o açúcar derreta"... Mas a experiência desta diferença é também o que comunica cada duração com o todo das durações, quando não com a duração do Todo.

A referência bergsoniana se mostra mais uma vez bastante útil para que nos situemos nos giros de linguagem contemporâneos. O que é revindicado pela expressão de "totalidade aberta", em Deleuze e em outros, não é nada mais que um princípio construtivo de prolongamento local. Toda duração, todo fragmento de experiência afeta outros, nada se fecha em si mesmo; podemos alcançar o Todo sem nunca ter de deixar o plano da experiência (o "plano de imanência", a "experiência pura"), seguindo as ondulações e as dobras de sua trama, as relações disjuntivas que faz com que as coisas se mantenham juntas sem parar de diferir umas das outras. Para quem prefere o vocábulo do ponto de vista e da perspectiva, temos aí a ideia de que, por fim, a toda representação que quisermos dar o espaço de composição das perspectivas será, por sua vez, uma perspectiva a mais. Este princípio William James enunciava claramente a respeito das "relações externas". A arma de guerra contra o monismo idealista - a tese segundo a qual existe essencialmente apenas um tipo de coisa, e que esta coisa tem a consistência da Ideia - toma, em seu pensamento, a forma de uma tese muito simples de enunciar: não somente as relações entre dois termos distintos devem ser pensadas como relações externas, ou seja, como relações que não se deduzem dos termos presentes, mas consequentemente toda relação deve poder

\footnotetext{
${ }^{25} \mathrm{E}$ a grande lição do texto estranho e genial intitulado "Le souvenir du présent et la fausse reconnaissance" (L'Énergie spirituelle, Paris: PUF, 2010), e que constitui a armadura conceitual da teoria da "imagem-cristal" apresentada por Deleuze em L'Image-temps (Paris: Minuit, 1985). O tempo flui, sem dúvida, mas à condição de que alguma coisa não passe, de que não envie, como em Kafka, à forma da permanência e à categoria de substância, mas ao fato metafísico da conservação integral do passado. O passado não é do inexistente, ou seja, do presente que foi, e que subsiste apenas através de seus traços. É o passado que é, enquanto o presente não cessa de passar.
} 
ser objeto de uma experiência local. É o princípio do pluralismo: toda relação de experiência é também, e necessariamente, uma experiência de relação. ${ }^{26}$ Esta experiência de relação se faz necessariamente do ponto de vista de um terceiro termo que se apresenta mais como uma ligação, um prolongamento ou uma extensão da experiência, do que um ponto de vista "geometral" que faria a volta uma vez por todas. "Interpretado em sentido pragmático, o pluralismo, ou a doutrina que admite a multiplicidade (many) no universo, significa simplesmente que as diversas partes da realidade podem manter relações exteriores. Qualquer que seja a coisa a qual se pense, tão vasta ou tão abrangente que seja, ela é, segundo a concepção pluralista, em um certo meio "exterior", e primordial, quaisquer que possam ser, de resto, a qualidade e a extensão deste meio. As coisas estão em relação umas com as outras de diversas maneiras; mas não há uma que encerre todas. Uma frase sempre arrasta atrás de si a palavra e, que a extende. Há sempre algo que escapa". ${ }^{27} \mathrm{O}$ jogo de relações não pode ser mergulhado em um espaço global que envolveria de só um golpe todas as relações, sem que este envolvimento deva ser pensado como uma relação suplementar. Não há conjunto de todos os conjuntos: algo sempre escapa (em bom francês: "Something always escapes"), e isto não nos condena ao pathos do singular, nem à invocação da existência irredutível ao conceito.

Uma perspectiva sendo finalmente apenas um feixo de relações ordenadas por um ponto de vista, não é difícil transpor esta intuição fundamental de uma totalidade dispersada para certas configurações artísticas contemporâneas (com a ideia de perspectiva móvel no cinema ou vídeo) ${ }^{28}$ As construções científicas, a nova física do movimento herdada de Eistein, autorizam manobras semelhantes: basta substituir a noção de perspectiva por aquela de referencial ou de "sistema de referência" pela descrição do movimento. Voltaremos a isto no parágrafo seguinte. De forma geral, os esquemas conceituais desenvolvidos pelo pensamento científico podem ser tomados como tantos mapas que permitem que nos localizemos na experiência, oferecendo vistas panorâmicas e sugerindo atalhos. Mas se seguimos James, cada novo mapa é ele mesmo uma extensão particular da experiência, que ele enriquece e prolonga. Falando como Bruno Latour, o mundo é plano. ${ }^{29}$ Tudo está no nível: o mapa é consoante à realidade; ele não a ultrapassa. $\mathrm{O}$

\footnotetext{
${ }^{26}$ Ver William James, Philosophie de l'expérience [A Pluralistic Universe], $7^{\mathrm{e}}$ leçon, Paris, 1910.

${ }^{27}$ Ibid., $8^{e}$ leçon, p. $309 \mathrm{~s}$.

${ }^{28}$ Permito me remeter aqui às análises que consagrei a esta questão em Faux raccords: la coexistence des images, Paris: Actes Sud, 2010, principalmente p. 18-25.

${ }^{29}$ Ver Bruno Latour, Changer de société - Refaire de la sociologie, Paris: La Découverte, 2006, principalmente p. 241-251.
} 
global é conquistado ao termo de um trabalho de ligação (raccordement) local, que nos condena a seguir o fio das mediações concatenadas que fazem com que as coisas, tão distantes estejam elas no tempo e no espaço, se mantenham juntas se apoiando umas sobre as outras. Não há a escolher entre saltar a experiência por cima utilizando mapas, ou abrir um caminho pelo meio: o atalho continua a ser um caminho, e saltar será sempre construir uma ponte ou um polder sobre o plano da experiência, ou seja, uma nova ligação, uma nova extensão. ${ }^{30} \mathrm{Em}$ suma, existem apenas maneiras de "localizar o global", ou, ao contrário, de "distribuir o local". É necessário falar de rede, mais do que de sistema.

Defendendo as últimas consequências da tese das relações externas, James tinha em vista o "block-universe", 31 esta figura da totalidade privilegiada pelo monismo idealista de Bradley, o hegeliano inglês: em um tal universo-bloco as coisas, tão diversas quanto as imaginemos, não teriam nem mais que se fazer. Em princípio dispostas umas em relação às outras em um espaço de relativização ideal, elas seriam somente diversas expressões do Todo. Compreendemos o que choca James: pensar tal espaço como real leva a reduzir todas as relações à relações internas - internas ao Todo das relações, um Todo tomado em bloco, em sua eternidade. Esta ideia encontra eco na concepção metafísica que postula, anteriormente à nossa ciência humana - que é ela perpetuamente devir e necessariamente situada -, uma ciência "em si", uma ciência integral que se confundiria com a realidade mesma e que nós nos limitaríamos a adquirir fragmento por fragmento. Esta miragem da mathesis universalis que Bergson não cessou de denunciar sustenta a maioria das disputas suscitadas hoje em dia nos espaços dos filósofos, pelo conceito físico de espaço-tempo de quatro dimensões. O uso filosófico "espontâneo" se livrou das imagens abusivamente realistas do receptáculo universal (espaço e tempo absolutos à la Newton); não continuamos menos frequentemente a dar ao espaçotempo o papel de um plano de inteligibilidade absoluta em que todas as coisas encontrariam seu lugar em relação à todas as outras. Aqui o desafio consistiria talvez em recolocar a forma espaço-tempo no jogo das perspectivas para tomá-la ela mesma - alguns físicos convidam a tal - como um mapa entre outros possíveis. ${ }^{32}$

\footnotetext{
${ }^{30}$ Desenvolvi esta questão em "Cartes et graphes: les usages du concept chez James et Bergson", in Bergson et James: cent ans après, S. Madelrieux (dir.), Paris: PUF, 2011.

${ }^{31}$ William James, Philosophie de l'expérience, op. cit., $2^{\mathrm{e}}$ leçon.

${ }^{32}$ Conferir, por exemplo, David Bohm, The Special Theory of Relativity, London, Routledge, 1996 [1965], p. 139s. Os pensadores da gravidade quântica (Lee Smolin, Carlo Rovelli, etc.) visam hoje fundar a física passando ao largo do espaço e do tempo, ou seja, mostrando de que maneira estes conceitos fundamentais (e a forma espaço-tempo ela mesma) podem ser derivadas do jogo dos fenômenos, de maneira puramente relacional.
} 


\section{Um classicismo torcido (tordu): o caso Einstein}

Compreendemos então que renunciar ao sistema, à resposta sistemática, não é se desfazer da questão da totalidade, mas colocá-la de outro modo. Bergson considera que as coisas somente se mantêm (e portanto coexistem) enquanto elas duram, ou seja, enquanto elas se fazem. Colocando as coisas desta forma, ele é necessariamente conduzido a perguntar-se como as durações se compõem no todo de um Universo que dura ele mesmo: é o desafio profundo de seu diálogo perdido com Einstein. Vimos que James encontra um problema da mesma ordem partindo da lógica das relações: é o desafio de seu diálogo com Bradley e a tradição idealista. Inversamente ao ideal clássico da mathesis universalis, a segunda modernidade de que somos herdeiros talvez terá consistido em afirmar que toda relação de experiência pode ser convertida em experiência de relação, ou, o que dá no mesmo, que toda composição de perspectivas tem forçosamente por contrapartida a libertação (dégagement) de uma nova perspectiva, de forma que a realidade permanece para sempre "aberta". Esta intuição nutre mais ou menos abertamente os pensamentos de Lévi-Strauss, de Deleuze, e de Latour hoje.

As dificuldades que existem para manter uma metafísica local sem renunciar definitivamente ao global coloca ainda algumas dificuldades, e talvez seja isto o que incitou alguns - Badiou principalmente - a se desfazer do conceito de perspectiva e da referência oblíqua à totalidade, para pensar diretamente o múltiplo puro - o múltiplo de um múltiplo não totalizável. No entanto, entre esta solução radical e o classicismo metafísico, há toda uma gradiente de posições intermediárias que as potências conjugadas da arte e da ciência permitem de apreender melhor. A referência extra-filosófica age aqui como um instrumento de precisão: ela permite a variação da ideia de espaço-tempo como enquadramento global do nexus de relações ou de perspectivas; ela permite ver, por exemplo, que um espaço-tempo pode ser perfeitamente regular, uniforme, simétrico e então "global" (no sentido de que sua forma é fixada de uma vez por todas), sem deixar de ser perfeitamente local (no sentido de que o princípio de ligação (raccord) entre as perspectivas é definido por operações estritamente locais, de modo que suas propriedades globais não são imediatamente dadas, mas podem somente ser descobertas ou inferidas ao fim de uma exploração que proceda pelo reestabelecimento das perspectivas). É o caso, em física, do espaço-tempo da relatividade limitada, que é compatível por direito com não importa qual espaço local "plano" mas globalmente curvado (do gênero cilíndrico, núcleo, fita de Möbius ou garrafa de Klein). Em meu 
livro Faux raccords, procurei demonstrar que o espaço-tempo fílmico e mental de Vertigo, o filme Hitchcock, devia ter uma estrutura global do tipo fita de Möbius (espaço de desorientação), ainda que só pudéssemos ter esta intuição a partir de falsas ligações locais.

Estes exemplos tomados de empréstimo à física e ao cinema sugerem, em geral, uma figura possível do classicismo na metafísica, e talvez na arte e na ciência: se trataria de um classicismo torcido ou quebrado, curvo (coudé). Podemos dar uma ideia disso ao lembrar que a teoria formulada em 1905 por Einstein, contemporânea do cubismo, instaurava no centro do pensamento dois axiomas cuja conjunção tinha uma visada metafísica imediata. Poderíamos resumir estes dois axiomas invocando duas obras do artista americano Dan Graham, produzidas alguns anos de distância: Two Correlated Rotations (1972) e Present continuous past(s) (1974). Estas instalações-vídeo incorporam respectivamente os dois princípios fundamentais que estão no coração da intervenção relativista: por um lado, um princípio de reciprocidade ou de equivalência radical entre as perspectivas (isto que os físicos chamam, desde Galileu, de "princípio de relatividade"); por outro lado, um princípio de localidade ou de ação em proximidade (este princípio os físicos identificam à ideia de uma velocidade limite finita, espécie de horizonte do espaço das velocidades, que corresponde neste caso à velocidade da luz no vazio). Dito de outra forma, a relatividade afirma duas coisas: 1) não existe ponto de vista privilegiado; 2) não existe ação à distância.

Examinemos estes princípios um após o outro.

A partir de um quadro de análise do tipo kantiano, poderíamos dizer que o princípio de reciprocidade cumpre o gesto da revolução copernicana iniciado por Kant, que permanecia ainda prisioneiro da ideia de um mundo "centrado" (no caso, sobre a perspectiva de um sujeito - ainda que universal de direito, posto que se trata na Critica da razão pura do sujeito do conhecimento, distinto do sujeito empírico). Realizar a revolução copernicana é reconhecer que o mundo não mais possui centro, que ele é não apenas infinito mas radicalmente descentrado, de modo que existem somente perspectivas móveis deslocadas umas sobre as outras, deslizando juntas no espaço e no tempo (ou melhor, constituindo todas juntas o que nós chamamos de espaço-tempo). Dentre todas essas perspectivas, nenhuma é privilegiada, senão por pura convenção, de maneira arbitrária, quando escolhemos descrever o mundo a partir de um posto de observação instalado em um dado referencial (a Terra ou o Sol). O transcendental kantiano tinha precisamente por função regrar a articulação das perspectivas umas sobre as outras, segundo uma exigência que era ao mesmo tempo forte e mínima, podendo ser enunciada assim: o que é tido em vista em uma perspectiva deve sempre 
poder ser traduzida em outra perspectiva. Na relatividade, um jogo de fórmulas algébricas, as transformações ditas "de Lorentz", assumem uma tal intertradutibilidade. Na metafísica, são as regras constitutivas de toda objetividade que garantem a possibilidade de recuperar uma invariância no centro de toda variação perspectiva. Toda a posteridade kantiana, até Cassirer e Piaget, empregou esta via.

Quanto ao princípio de localidade, ele pode ser compreendido como uma reação do princípio de causalidade sobre o princípio de ação recíproca que formulam, respectivamente, a segunda e a terceira "analogia da experiência" da Crítica da razão pura. Nesta seção célebre de sua grande obra, Kant busca estabelecer, se apoiando notadamente sobre o tempo como forma a priori da intuição, as condições de possibilidade de uma representação dos fenômenos enquanto submetidos a uma ligação necessária - e assim, de uma representação da natureza como submetida a leis. "Todos os fenômenos, escreve ele, são submetidos a priori, quanto à sua existência, a regras que determinam suas relações entre si em um tempo". A segunda analogia introduz o conceito de sucessão, inseparável da ideia de causalidade. A terceira analogia introduz o conceito de ação recíproca, cuja função é de tornar pensável o nexus das coisas, a interação universal, a comunidade ou a coexistência dos fenômenos. É a simultaneidade que fornece aqui o fio condutor: todas as substâncias, enquanto puderem ser percebidas ou pensadas como simultaneidades no espaço, estão "em uma ação universal recíproca". Mas de um ponto de vista objetivo, submeter todas as velocidades a um princípio de limitação, como propõe Einstein, é fazer reagir o princípio de causalidade sobre o princípio de comunidade ou de ação recíproca: é reintroduzir a ação local (inseparável de uma concepção local da causalidade) no centro do esquema da ação universal. É distender, e talvez finalmente deslocar, as relações de simultaneidade tais como se as figurássemos classicamente. Sabemos que um dos resultados mais impressionantes da teoria da relatividade é o de estabelecer que a determinação de uma relação de simultaneidade entre dois acontecimentos distantes é necessariamente relativa ao ponto de vista adotado, ou seja, ao referencial ou à velocidade relativa. A força de Einstein está em mostrar que é este o preço a pagar por uma extensão universal do princípio de relatividade (ou de reciprocidade). Kant, que tinha todas as razões para desconfiar do espaço e do tempo absolutos à la Newton, esteve perto de pagar este preço? Sem dúvida não, e não foi sem dificuldade que os neo-kantianos e os neo-positivistas se esforçaram, por diferentes vias, de se desvincular deste problema durante o século XX.

Este desvio pelo modo de conceitualidade crítica possuía apenas uma função: demonstrar de qual maneira um certo acoplamento das noções 
de perspectiva e de localidade podia chegar, como bem viu Bergson, a desfigurar o universo clássico inserindo uma espécie de canto no modo de racionalidade que sustentava sua construção. ${ }^{33}$ Notemos que é o segundo princípio, o princípio de localidade, que é responsável por esta modificação. Implica que só pode haver ligação pouco a pouco, ou seja, "localmente". Sem ação à distância, sem ação instantânea (à velocidade infinita): este princípio de limitação significa, concretamente, que toda ação, toda interação exige tempo. Daí resultam os famosos paradoxos relativistas que vêm esmigalhar o espaço-tempo clássico: deslocamento da simultaneidade, contração de distâncias, dilatação das durações, etc. O pensamento do nexus se encontra singularmente complicado, e a nova figura do Todo que se descola sobre o fundo da revolução einsteiniana, o espaço-tempo que totaliza o conjunto das perspectivas móveis obriga a estranhas contorções: não é lugar para entrar em detalhes. Contentemo-nos em dizer que Dan Graham é nisto contemporâneo de Einstein: introduzindo na video-performance um duplo princípio de reciprocidade e de localidade, ele faz ver e sentir as falsas ligações que resultam da ação conjugada do princípio de reciprocidade e do princípio de localidade.

A primeira peça, Two Correlated Rotations, emprega, literalmente, um princípio de reciprocidade, forçando duas perspectivas a se ajustarem uma sobre a outra tanto quanto possível durante toda a duração do filme, ao ponto de anular qualquer possibilidade de apreensão sinóptica. A segunda peça, Present Continuous Past(s), é filmada segundo o princípio do efeito de retardador (l'effet à retardement): uma diferença temporal ("time delay") de oito segundos adicionada ao jogo de espelhos e ao efeito de larsen vídeo compõe um espaço-tempo estratificado, ou fractal. Minando a evidência do "presente" vivido, a ruptura escalonada das relações de simultaneidade reenvia o espaço mesmo à sua ambiguidade, e assim torna palpável, através do procedimento, um princípio de ação retardada que é formalmente equivalente a este princípio de localidade que aqui associamos à ideia de velocidade-limite, ou de horizonte.

Em suma, Dan Graham cumpre dois gestos simétricos: com as duas rotações correlacionadas, ele extingue toda possibilidade de recuo perspectivo; com Present Continuous Past(s) ele perturba a lógica do circuito fechado ao nela injetar, ao contrário, um movimento de recuo, e então uma perspectiva espacial e temporal deslocada, errática e discontínua, que corresponde à sua ambição, formulada em relação à outra peça, de produzir algo como um "espaço-tempo discontínuo, não progressivo", em que as relações tornar-se-iam "quase simultaneamente

${ }^{33}$ Ver Henri Bergson, Durée et Simultanéité, Paris: PUF, 2009, p. 426-427. 
disponíveis como perspectivas, (mas) sem densidade nem localização espaciais". ${ }^{34}$

\section{Um nexus disperso}

Estas considerações um pouco digressivas, distribuídas sobre diversas "linhas de fatos", convergem, no entanto, em direção a uma mesma ideia, uma mesma proposição que poderia ser esta de uma metafísica preocupada, por um lado, em não abandonar tão facilmente a totalidade, e, por outro, em não recair nos antigos reveses (travers) do espírito de sistema. Se trataria de dar-se os meios de pensar uma totalidade dispersa, um nexus não somente plural, mas fragmentado e mesmo, por que não, perfurado. Estas imagens - porque são imagens - deveriam sugerir que existem, na realidade, regimes de coexistência que devem ser pensados juntos e em sua diferença. O nexus não é necessariamente um plenum: ele deve acolher zonas de indeterminação relativa, e talvez graus variáveis de existência e de coexistência. ${ }^{35}$ Novamente, William James havia sentido bem o problema quando respondia aos idealistas e aos amigos do "block-universe" que a questão não era escolher entre uma "independência absoluta" que manteria as coisas em um estado de isolamento e de separação, e uma "absoluta e mútua dependência" que as faria uniformemente se comunicar no cerne da totalidade. Esta alternativa abstrata, a pegar ou largar, não corresponde à realidade das coisas: "O que diz o pluralista, é que é possível que o universo esteja conectado de maneira frouxa (connected loosely), tal como nossa experiência cotidiana...". ${ }^{36}$ Para pensar de forma rigorosa uma tal coexistência distendida, nós precisamos de um método. O sistema seguirá se ele puder; mas é provável, e sem dúvida desejável, que não tenhamos então um método, mas vários.

Tradução de:

Gabriela Jaquet

Mestranda (CNPq), PPG em História, UFRGS.

\section{Endereço postal:}

Département de Philosophie - Université Paris Ouest Nanterre La Défense

200 Avenue République

Nanterre, 92001

Data de recebimento: $26 / 03 / 2014$

Data de aceite: 29/05/2014

\footnotetext{
${ }^{34}$ Sobre tudo isto, ver Faux raccords, op. cit.

${ }^{35}$ Poderíamos, sobre esta questão, seguir as pistas lançadas por Étienne Souriau em Des différents modes d'existence [1943], Paris: PUF, 2010.

${ }^{36}$ William James, Philosophie de l'expérience, op. cit., $2^{\mathrm{a}}$ lição.
} 